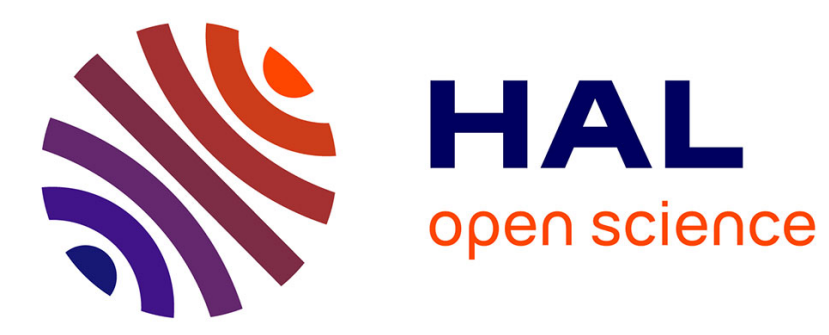

\title{
A new method of making metal matrix fibre reinforced materials
}

\author{
J. Schaupp, R. Prümmer
}

\section{To cite this version:}

J. Schaupp, R. Prümmer. A new method of making metal matrix fibre reinforced materials. Journal de

Physique IV Proceedings, 1993, 03 (C7), pp.C7-1731-C7-1735. 10.1051/jp4:19937272 . jpa-00251913

\section{HAL Id: jpa-00251913 https://hal.science/jpa-00251913}

Submitted on 1 Jan 1993

HAL is a multi-disciplinary open access archive for the deposit and dissemination of scientific research documents, whether they are published or not. The documents may come from teaching and research institutions in France or abroad, or from public or private research centers.
L'archive ouverte pluridisciplinaire HAL, est destinée au dépôt et à la diffusion de documents scientifiques de niveau recherche, publiés ou non, émanant des établissements d'enseignement et de recherche français ou étrangers, des laboratoires publics ou privés. 


\title{
A new method of making metal matrix fibre reinforced materials
}

\author{
J. SCHAUPP and R. PRÜMMER*
}

Institut für Werkzeugmaschinen und Betriebstechnik, University of Karlsruhe, Germany

* Ernst-Mach-Institut, Freiburg, Germany

MMC (metal matrix composites) made of ceramic fibres and metal matrix are suitable for high strength and high temperature applications. New types of ceramic fibres usually are incorporated into a metal matrix by means of liquid infiltration or by hot pressing techniques. The disadvantage of these methods is the chemical reaction sometimes occurring between fibre and matrix, resulting in an interlayer which is degrading the mechanical properties of the MMC. A new method is described starting with an arrangement of metal powder or metal foils with ceramic fibres. Dynamic pressures, released by detonation of proper explosives, are used for consolidation. At very high strain rates during plastic deformation of the powder or metal foils hydrodynamic flow of the matrix around the ceramic fibres allows a complete consolidation and to prevent cracking. Fibres made of SiC are embedded into a metal matrix of aluminum. 


\section{INTRODUCTION}

Currently used methods for the development of MMC's (Metal Matrix Composites), existing of ceramic fibres and a metal matrix are hot pressing and liquid infiltration. Ceramic fibres existing of $\mathrm{SiC}$ are very interesting for reinforcing metals as they reveal high strength. Fabricated by means of CVD-techniques at diameters of about $100 \mu \mathrm{m}$, these ceramic fibres behave mechanically brittle. Therefore brittle fracture is likely to occur in hot pressing. On the other hand, due to high processing temperatures during fabrication, especially in the case of liquid infiltration, diffusion layers at the interphase of metal matrix and ceramic fibre are formed, thereby weakening the composite.

It has been shown that explosive methods are suitable to make metals reinforced with fibres. Ceramic fibres, however, showed brittle behavior (1). In the meantime, however, a new generation of ceramic fibres has been created.

Such fibres, existing of $\mathrm{SiC}$ at diameters of about $100 \mu \mathrm{m}$ are investigated and found suitable for making MMC's by means of explosive compaction. It is necessary to select proper conditions of consolidation.

\section{METHOD OF EXPLOSIVE COMPACTION}

The most common method currently used is the direct method: a cylindrical container is surrounded by a uniform layer of an explosive. When the detonation is initiated at the upper end, a shock wave is proceeding towards the center of the container compacting the contained powder. In order to achieve a uniform compaction (homogeneous density over the cross section), the magnitude of the shock wave and its duration have to meet requirements which can be met by the use of proper type of explosive in a proper amount. The pressure $p$ is related to the detonation velocity $v_{D}$ and the density of the explosive by the equation

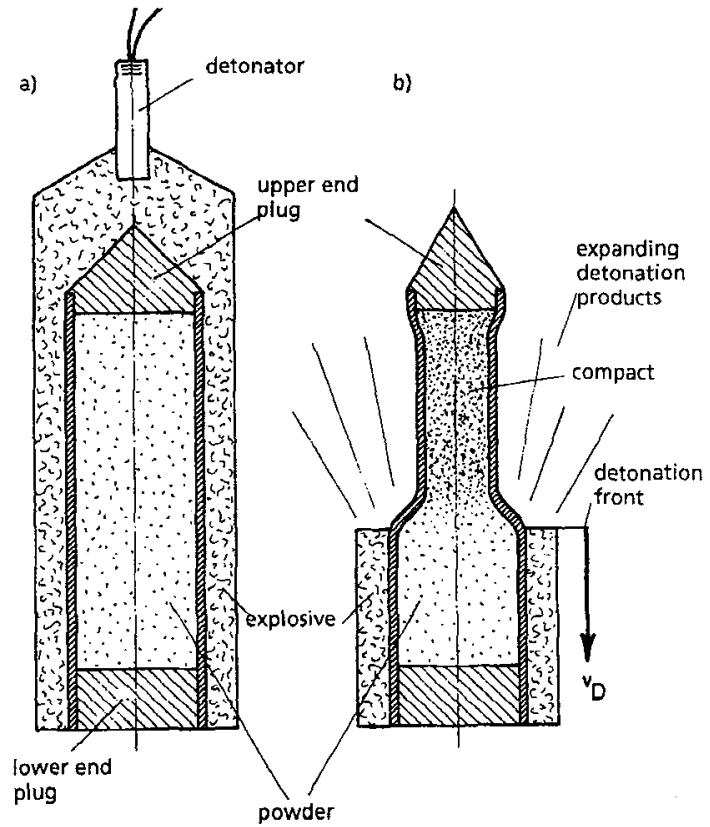

$$
\mathrm{p}=1 / 4 \rho \mathrm{v}_{\mathrm{s}}^{2}
$$

It has been shown that there exists a linear relationship between the required pressure for densification and the hardness of the powder particles (2).

Fig. 1 shows the arrangement for explosive compaction. In the case of an ideal compaction, the shock wave front in the sample is of the shape of a hollow cone as shown in the case of b) of Fig. 2. This fact can be checked experimentally by the use of X-ray flash or by electronic means and by means of computer modeling as well (3).

\section{Arrangement of Explosive Compaction}

\footnotetext{
a) before initiation
b) after initiation

Fig. 1
} 


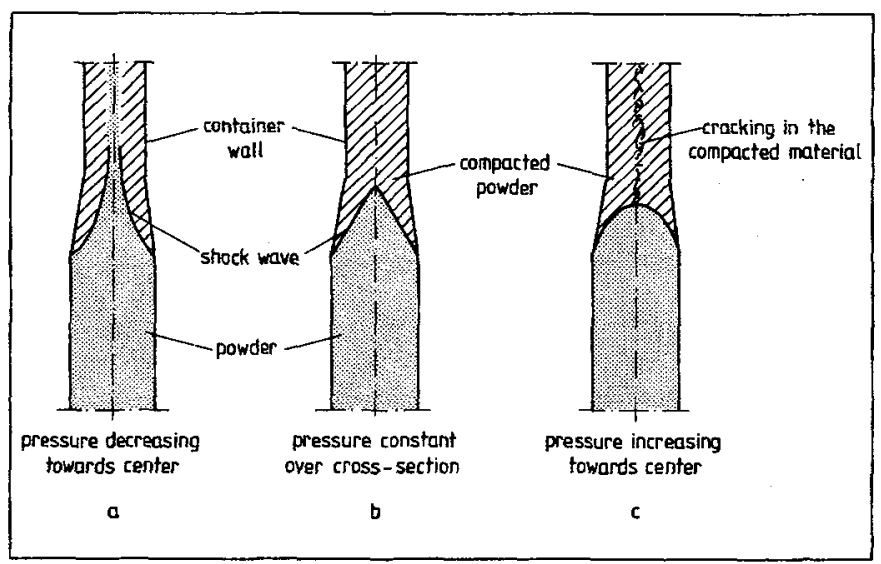

Shock wave Configuration in case of

a) unsufficient compaction

b) correct compaction

c) too severe compaction

Fig. 2

\section{ASSEMBLIES FOR EXPLOSIVE INCORPORATION OF CERAMIC FIBRES INTO A METAL MATRIX}

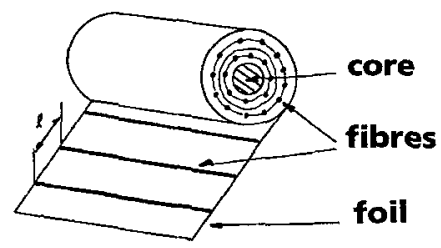

Winding of Foils with Fibres

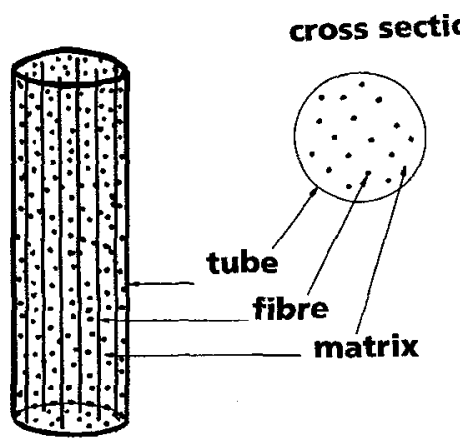

Arrangement of Fibres with powder

\section{Cylindrical Arrangements ig. 3 of fibres with matrix}

Both uniform and random distribution of ceramic fibres in a metal matrix can be performed. In the case of a cylindrical sample with unidirectional reinforcement, the procedures shown in Fig. 3 can be applied. A metal foil is covered with fibres by means of a special winding technique described in (1) and then spirally wound. In subsequent explosive compaction of this cylinder the different layers of the metal foils are welded incorporating the ceramic fibres in the metal matrix. On the other hand, a parallel arrangement of the ceramic fibres in a cylindrical sample as shown in the lower part of Fig. 3 is feasible. Experiments were performed with an aluminum foil (cold rolled $99.9 \% \mathrm{Al}$, Goodfellow metals) of .1 mm thickness and with an aluminum powder (type Eckart $\mathrm{Al} 011$ ) with a mean particle size of $30 \mu \mathrm{m}$. The SiC-fibres shown in Table 1 were used for the tests.

\section{EXPERIMENTAL EVALUATION}

Tests performed under different pressures were performed using explosives with different detonation velocities at various amounts with respect of the mass of the powder or foil/fibre mixture. Investigations performed after cutting the compacted samples in an area perpendicular to the axis of the specimen were made by metallographic means and by scanning electron microscopy. It was fount that at high pressures $\mathrm{P}$ (calculated according to equation 1) larger than $2.5 \mathrm{GPa}$ fracturing was very likely to occur. Also at low pressures, $\mathrm{P}<0.67 \mathrm{GPa}$ but 


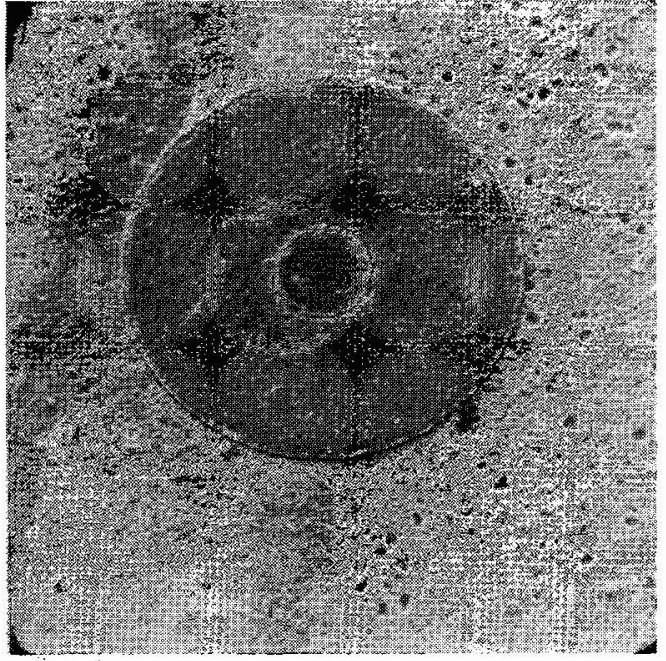

Sic-fibre embedded in Al (foil), detonation pressure $=.67 \mathrm{GPa}$, SEM-picture with longer duration ( $\mathrm{t}>10 \mu \mathrm{s}$ ) cracking was observed to a large extend. In between, a range is existing where all ceramic fibres survive the shock treatment during consolidation without fracture and a complete flow of the matrix material around the fibres is observed without leaving any voids. Figs. 4 and 5 show an AVCO fibre embedded in $\mathrm{Al}$ both in cross section and longitudinal direction.

In a larger magnification the same fibre is shown in Fig. 6. There are no voids in the matrix left and there is no diffusion layer observed at the interphase between fibre and matrix. Fig. 7 shows a BP fibre embedded in the same manner into aluminum. Also in this case the fibre is totally surrounded by the aluminum matrix and there are no voids left in the aluminum matrix.

\begin{tabular}{|l|l|l|l|c|}
\hline Name & made by & spec. gravity & diameter & tensile strength \\
\hline SCS-6 & AVCO & $3.05 \mathrm{~g} / \mathrm{cm}^{3}$ & $140 \mu \mathrm{m}$ & $4000 \mathrm{MPa}$ \\
SM 1040 & BP & $3.4 \mathrm{~g} / \mathrm{cm}^{3}$ & $100 \mu \mathrm{m}$ & $3500 \mathrm{MPa}$ \\
\hline
\end{tabular}

Table 1 Properties of used fibres

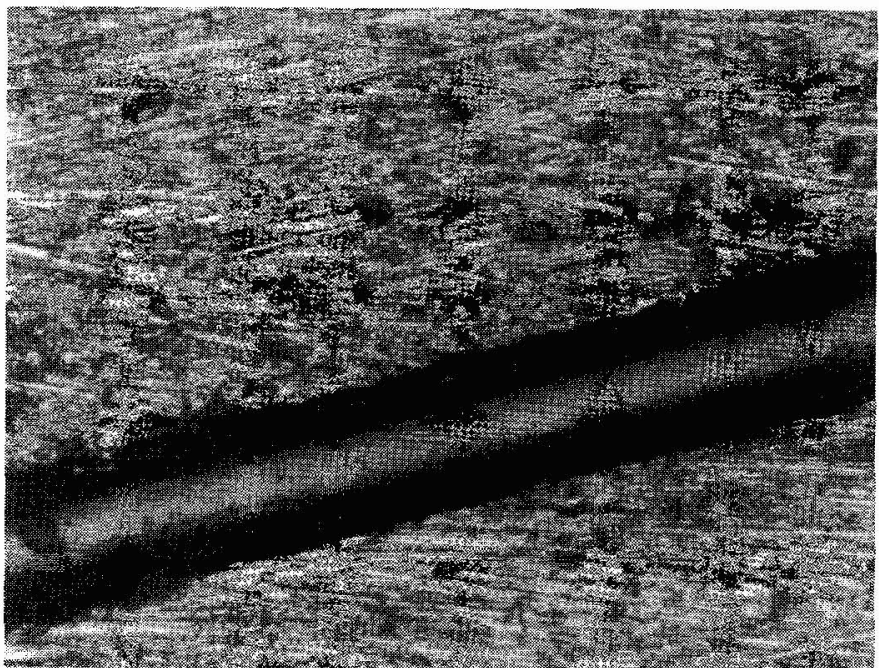

SiC- fibre, embedded into Al-matrix (foil), detonation pressure $=.67 \mathrm{GPa}$,

Fiq. 5 SEM, longitudinal section. 


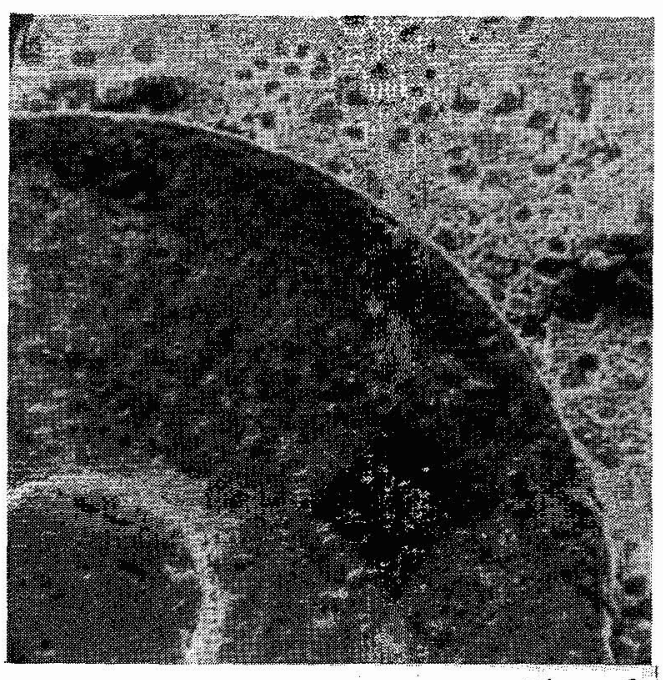

Sic fibre embedded in Al (foil),

detanation pressure $=.67 \mathrm{GPa}$, SEM picture

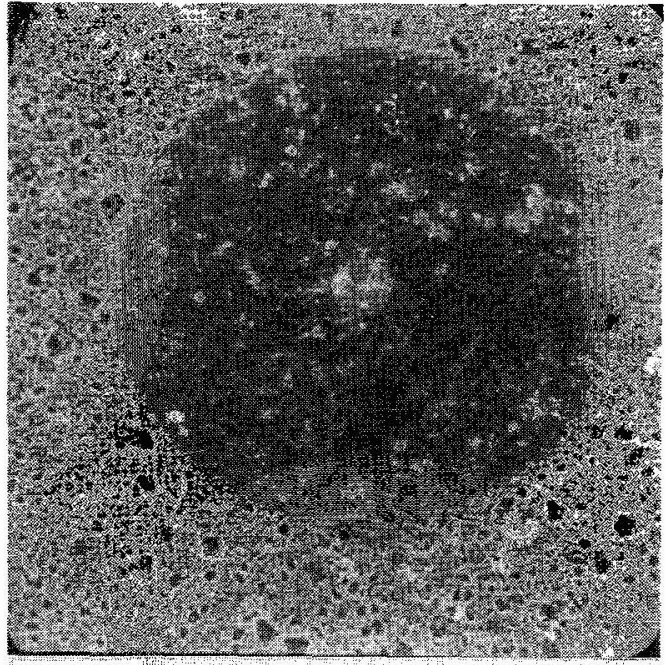

Fig. 7

$$
\begin{aligned}
& \text { sic fibre embedded in Al (foil), } \\
& \text { detonation pressure }=.67 \mathrm{GPa} \text {, SEM picture }
\end{aligned}
$$

\section{CONCLUSIONS}

The unexpected result was obtained that ceramic fibres can be embedded into an aluminum matrix by shock techniques under the condition that proper parameters are chosen. Usually only the destructive effects of explosives are known and at a first glance one would expect many fragments of the fibres in a metal matrix. There is a strain rate effect responsible for this behavior. Such a strain rate dependent behavior has been observed in explosive forming and explosive welding $(4,5)$. Some materials at high velocity deformation show regimes where elongation during forming increases and brittle ductile behavior is occurring. At this moment it is not yet clear whether the matrix or the fibres are responsible for this behavior. Hydrodynamic flow of the matrix around the fibres as observed in a similar manner under conditions of explosive welding could account for this effect. On the other hand, a more ductile response of the ceramic fibres to shock wave loading could contribute to this effect. The effect seems to apply to different fibres. Further investigations are necessary to investigate the compound itself.

\section{LITERATURE CITED}

[1] WOLF E. and PRÜMMER R., Explosive Herstellung faserverstärkter Metalle. Raumfahrtforschung Heft 1, Jan. Febr. 1973, $20-28$.

[2] PRÜMMER R., Explosivverdichtung pulvriger Substanzen. Springer-Verlag, Bln., Hdbg, New York, London, Paris, Tokyo 1987, ISBN 3-540-17029-4, ISBN 0-387-17029-4.

[3] REAUGH J, , Computer Simulations to Study the Explosive Consolidation of Powders into Rods. J. Appl. Phys. 61 (3) 1. Feb. 1987.

[4] PRÜMMER R., Explosive Welding of Metallic Glasses onto Metals. Z. Werkstofftechnik 13 (1982), 44 - 48.

[5] PRÜMMER R., Explosive Welding of a Molybdenum High Temperature Resistant Alloy Compound. Proc. 7th Int. HERF Conf. Leeds, Sept. 1981, 186 - 191. 